\title{
«El mejor arbitrio, el sermón». Discurso religioso y representación política en el Perú del siglo XVII/
}

«El mejor arbitrio, el sermón».

Religious Discourse and Political Representation in Seventeenth-Century Peru

\author{
Carlos M. Gálvez Peña \\ Pontificia Universidad Católica del Perú
}

El artículo analiza el significado histórico de los arbitrios escritos por intelectuales de las órdenes franciscana, dominica y jesuita en el Perú entre 1630 y 1659. En particular, se estudia su impacto para negociar una cuota de representación política para las órdenes y las elites del virreinato peruano en este período. Adicionalmente, estos memoriales son vistos como expresión de la modernidad teórica de la iglesia criolla en la era de la confesionalización.

PAlabras ClaVE: Arbitrio; Memorial; Representación; Monarquía compuesta; Confesionalización; Benemérito; Orden religiosa; Cuerpo político; Monarquía católica.

The article studies the historical significance of four projects (arbitrios) written by religious scholars from the Franciscan, Dominican and Jesuit orders in Peru, between 1630 and 1659. In particular, it studies the impact of these projects in the negotiation for political representation with the Crown. The article also addresses the importance of these projects as expression of the theoretical modernity of Peru's creole church in the era of Confessionalization.

Keywords: Arbitrio; Memorial; Representation; Composite Monarchy; Confessionalization; Benemérito; Religious Order; Body Politic; Catholic Monarchy. 
En la historia de la representación política virreinal poca atención se ha prestado a ciertos géneros del discurso religioso que constituyen legítimas fuentes para el estudio de las agendas políticas de las elites urbanas e intelectuales de los reinos americanos. Es el caso de la tradición arbitrista/memorialista tan pujante en la península ibérica desde fines del siglo XVI y sobre todo en el XVII, tradicionalmente analizada desde una sola perspectiva. El arbitrismo/memorialismo ha sido entendido casi exclusivamente como la expresión de la argumentacion legal, y por ende como un discurso eminentemente jurídico y secular, si bien recientes estudios han reconocido su permeabilidad y los varios ángulos temáticos que el género encierra. ${ }^{1}$ El problema radica en que al analizar este discurso centrándose en el debate de temas legales, políticos y económicos de relevancia imperial se suele dejar de lado la evidente intersección de estos con el discurso religioso también presente; componente importantísimo para entender correctamente la propuesta de reforma del cuerpo político de la monarquía católica que este discurso promovió. Tampoco se ha estudiado el arbitrismo/memorialismo como la expresión de las demandas de mayor representación y derechos de las elites intelectuales, representantes del grupo social conocido como los beneméritos americanos. Los autores de memoriales y arbitrios en el Nuevo Mundo, si bien escribieron desde las corporaciones religiosas que los formaron como sus voceros, no dejaron jamás de representar los intereses del grupo al que pertenecieron y de hecho intersectaron el mensaje religioso de sus corporaciones con las demandas políticas de las primeras.

Acaso la porosidad y la elasticidad de la producción memorialista de los siglos XVI y XVII — que abarcó los reinados de Felipe II al IV - tenga relación con el hecho de que nació en un momento a la vez fundacional del imperio hispano pero de percibida crisis política y financiera, acentuada particularmente en las primeras tres décadas del siglo XVII. El universo de opiniones - utilizando el título de la obra de Miguel Luque, la más sistemática y completa sobre el género— que buscó la reforma y la cura del cuerpo político español, abordó casi todo tema posible en el ámbito jurídico-teológico, como correspondía a propuestas que usando el utillaje legal

1 Miguel Luque define el memorial como un género jurídico-literario muy usado en las Indias, mediante el cual se solicitaba una gracia, fundamentando las circunstancias legales y el hecho sobre el que se cimentaba la solicitud. Reconoce con Basadre que encasillar al memorial en la literatura jurídica solamente es parcial dada la diversidad de temas históricos, religiosos, etc. que trataron. Luque Talaván, 2003, 223 y 253. 
civil y canónico, procuraron aportar un diagnóstico y una solución a los temas cruciales de la construcción del aparato imperial. ${ }^{2}$ Al concebir al derecho, la religión y la moral como principios ordenadores de la sociedad era natural la superposición de enfoques disciplinarios, la dificultad para aislar temáticas en el género $\mathrm{y}$, en general, la multiplicidad de agendas al interior de este discurso. ${ }^{3}$

Hace algunos años, el trabajo de Helen Rowlings contribuyó a nuestro entendimiento del arbitrismo como literatura de reforma del cuerpo político de la monarquía española y a su intersección con el problema religioso. Rowlings planteó la sugerente idea de que dada la tendencia secular y de crítica a la iglesia presente en el arbitrismo español —en particular aquel conjunto de memoriales producido entre 1615 y 1625 - , reflejaría una tendencia intelectual de apoyo al fortalecimiento del estado monárquico mientras que promovía la erosión de una desacreditada institución eclesiástica. Este arbitrismo anticlerical buscaba la modernización de la economía, que veía mermada por la concentración de recursos humanos y monetarios en manos de las corporaciones religiosas. Para Rowlings, el pico de la producción arbitrista coincidió precisamente con el crecimiento de la iglesia castellana a ambos lados del Atlántico. Exponente de esta visión sería la popular obra Conservación de Monarquías de Pedro Fernández de Navarrete, publicada en 1625; obra que en efecto criticó duramente el poder de las corporaciones eclesiásticas. ${ }^{4}$

El trabajo de Rowlings, si bien centrado en la obra de Navarrete, puso de relieve un aspecto soslayado: que la producción de memoriales, casi siempre a cargo de teólogos y canonistas, tuvo en no pocas oportunidades como objetivo la crítica a la propia iglesia. Es decir, que intelectuales religiosos podían escribir contra la iglesia y, en particular, contra la corporativa, las órdenes religiosas. Lo que Rowlings no se planteó fue que de esta cantera surgieran también los voceros para contestar a las críticas planteadas contra las corporaciones religiosas y elaborar argumentos para

2 Por ejemplo, el hecho de que en el frondoso catálogo de arbitrios que presenta Miguel Luque Talaván se consideren los escritos de fray Miguel de Agia, Tratado que contiene tres pareceres (1604), Feliciano de Vega, Alegación en derecho de los catedráticos de teología y cánones (1623), Gaspar de Villaroel, Govierno eclesiástico y pacífico (1656), fray Juan Zapata y Sandoval, De justicia Distributiva y la Acepción de Personas (1609) y fray Antonio Remesal, Historia de la Provincia de San Bernardo de Chiapa (1619), es altamente revelador de la flexibilidad del género, que va desde debates sobre derecho civil y canónico hasta historia. Luque Talaván, 2003.

3 Luque Talaván, 2003, 192

4 Rowlings, 2006. 
defenderse de ataques como el de Navarrete o la corona. No se ha enfatizado suficientemente el hecho de que temas discutidos en el interior de los memoriales y que hoy son vistos como de naturaleza «jurídica» por el tono de la argumentación, se conectaran de manera estrecha con problemas teológico-políticos y con agendas de propaganda a favor de las corporaciones religiosas. ${ }^{5}$ Para entender los argumentos y el tono de la defensa de estas últimas, hay que considerar lo que Michael Gordon definió como el énfasis en la «ciencia de la política» presente en el mensaje del arbitrismo del siglo XVII hispano, porque - agrego yo - los arbitristas, y en particular los memorialistas religiosos, entendieron que el sujeto de reforma de esa «ciencia de la politica» era, como quería la doctrina anti-maquiávelica, el cuerpo político de la monarquía y, en última instancia, la reorganización del estado. ${ }^{6} \mathrm{Si}$ se les atacaba por no contribuir a la construcción y consolidación del estado moderno, la respuesta de los arbitristas religiosos fue proponer -inspirados en la teoría anti-maquiavélica - la confesionalización del estado. ${ }^{7}$ Quiero en este artículo ahondar en la reflexión sobre el tema y proponer ejemplos de la tradición arbitrista del siglo XVII en el Perú, que afirman el hecho de que el arbitrismo religioso peruano, al ser entendido por sus autores como parte de la ciencia política que buscaba la reforma de la sociedad y el estado españoles, también replanteó - $\mathrm{O}$ al menos así lo imaginó- la relación entre la corona y el clero regular peruano, pues al buscar mayor margen de representación para la elite virreinal limena, el arbitrismo religioso producido en la ciudad de Los Reyes afirmó su creencia en la hegemonía imperial del brazo de las órdenes. Esta tendencia de pensamiento, curiosamente, no ha sido estudiada en relación con el memorialismo peruano, mientras que Magdalena Chocano lo ubica claramente en el caso mexicano, donde a través de diversos géneros de textos religiosos el clero novohispano legitimó sus demandas de mayor

5 Recientemente me he ocupado de los memoriales escritos por un prominente obispo limeño del siglo XVII que revelan nuevas visiones de la elite criolla sobre aspectos relativos a la doctrina de la prelación y la aplicación del Real Patronato en América. Gálvez-Peña, 2012b.

6 El anti-maquiavelismo es la adaptación católica de la razón de estado propuesta por la doctrina maquiavélica del estado moderno. Para mantener el estado, había que mantener a Dios «satisfecho y propicio» como sostenía Ribadeneyra. El estado no podía prescindir de la religión. Skinner, 2012, 172-173.

7 La época de la confesionalizacion, básicamente el siglo XVII, se caracterizó por la relación entre la iglesia y el orden secular, en la que ambos estaban estructuralmente entretejidos y eran funcionalmente interactivos. En este contexto se hizo posible que la burocracia religiosa europea diseñase partes del estado moderno. Para el historiador alemán Heinz Schilling, este momento puede considerarse el «umbral de la modernidad» (Vorsattelzeit des Moderne). Schilling, 2008, 14-15. 
importancia social afirmando, al mismo tiempo, la vigencia del orden imperial. ${ }^{8}$

La relación entre arbitrismo y representación es uno de los aspectos más relegados en el estudio del género, pero ciertamente el de mayor importancia para efectos de la lectura y comprensión de su mensaje político. Desde el siglo XVI las elites indianas buscaron canales para hacer efectiva su participación en la toma de decisiones relativas a América y asegurar una cuota de representación. Los estudios de Guillermo Lohmann y Demetrio Ramos han esbozado el cuadro inicial de las prácticas de representación en los intentos de convocar cortes en el ámbito hispanoamericano. En el Perú, el primer intento de participación política de la elite encomendera en cortes se dio precisamente para discutir las Leyes Nuevas en 1544, pero no sería sino hasta 1559 cuando se daría la primera convocatoria real de cortes para pedir una contribución a los vecinos beneméritos del Perú. ${ }^{9}$ Ramos sostiene que hubo que esperar hasta 1635 para que las principales ciudades del Nuevo Mundo, México y Lima, fueran formalmente autorizadas a enviar procuradores a cortes para la proclamación de príncipes, la asamblea de mayor rango político del reino, situación que igualó a las urbes americanas con sus pares peninsulares. Sin embargo, la norma quedó en el papel, pues en la práctica las ciudades indianas no enviaron representantes para este fin sino que fueron las corporaciones religiosas y seculares las que lo hicieron de manera regular y para fines diversos a lo largo del siglo usando la preeminencia y el capital simbólico asociado a la norma original. Adicionalmente, afirma Ramos que el hecho de que los procuradores fuesen rentados añadía atractivos y poder al cargo, con sueldos que ascendían al 1,5\% por cada mil pesos, además de beneficiarse de

8 Ver el caso de la recepción del anti-maquiavelismo en México que Magdalena Chocano ha estudiado. La autora sostiene que la elite religiosa letrada se apropió del anti-maquiavelismo para impulsar el proyecto imperial de los Austrias. Hay en esta tendencia de pensamiento dos vertientes: la «secular» o civil, que no tuvo mucho impacto después de 1640, fuera de la obra de Carlos de Sigüenza, Teatro de las Virtudes Políticas (México, 1680), y la tendencia palafoxiana, que usó abiertamente los contenidos y las instituciones religiosas para expresar su mensaje político ya desde mediados del siglo XVII. La Breve Relación de las Solemnísimas Exequias para el entierro del Ilustrísimo Feliciano de Vega escrita por Alonso Fernández Ossorio (México, 1642), por encargo del obispo Juan de Palafox, ejemplifica esta tendencia. Chocano, 2000, 262-263, 268-269 y 296.

9 Lohmann señala que las instrucciones recibidas por el virrey marqués de Montesclaros fueron de no convocar cortes en Lima, porque «un oficioso arbitrista había planteado el pedido» ante el consejo de Indias y así eran injustificadas. Pese a que la corona no fue particularmente proclive, el cabildo de Lima solicitó que la ciudad tuviera voto en cortes en sesión de septiembre de 1611 y lo hizo nuevamente en 1620. El conde de Chinchón recogió ese clamor y solicitó cuatro plazas con voto en cortes de Castilla. Lohmann Villena, 1990, 596, 601, 606 y 609-610. 
un fondo de gastos que alcanzaba los 60.000 ducados..$^{10}$ La existencia de esta prerrogativa revistió al procurador de Indias —a los ojos de los cabildos americanos - de una legitimidad indiscutible frente a la corona, pues los representantes de Lima y México tenían el rango de embajador cuando eran recibidos en la corte de Madrid. ${ }^{11}$

No es casual entonces que el memorialismo religioso peruano tuviera su época de auge en la primera mitad del siglo XVII y ello fuera posible por la vigencia de la red de procuradores religiosos que cruzaron el Atlántico con encargos de las corporaciones religiosas y, en menor medida, de las seculares. El hecho de que existiera el canal — dotado además de preeminencia simbólica - para el envío de los representantes a cortes de las ciudades promovió la producción de memoriales y arbitrios, y determinó también el tono de las demandas. Ahora bien, como ha sostenido Ignacio Pérez-Fortea, el sistema de cortes bajo los Austrias, concebido para autorizar impuestos extaordinarios, paulatinamente aisló al clero y a la nobleza de las decisiones sobre estos asuntos. Pero, al ser las corporaciones religiosas las más poderosas fuentes de financiamiento que tuvo la corona en Castilla y en América, con el tiempo — precisamente entre 1629 y 1656 - las órdenes manifestaron su voluntad de ser consultadas en sus propias congregaciones y a través de sus procuradores. Si bien carecían de representación política efectiva, fueron los procuradores de las órdenes religiosas los únicos agentes de las ciudades americanas que consiguieron pasar a la corte, mover los asuntos de interés local y hasta manifestarse en contra de la presión fiscal de la corona, aunque no siempre con éxito. ${ }^{12}$ El sistema de procuradores mantuvo viva por varias décadas, no solo la circulación sino la demanda por mayor representación expresada en arbitrios y memoriales, fusionando las expectativas de las religiones con aquellas de las elites urbanas. ${ }^{13}$ Con los ejemplos que a continuación comentaré, quiero presentar también una visión alternativa del arbitrismo religioso producido en Lima entre 1630 y 1659, y destacar su conexión con la crónica histórica y la oratoria sagrada, lo que abunda en la complejidad del género y su significado.

10 Pérez Ramos, 1990, 647.

11 Pérez-Fortea, 2007, 151.

12 Sobre las presiones fiscales de la corona en Castilla y sus efectos constitucionales en la percepción de la monarquía, ver Elliott, 2009, 182-183.

13 Pérez-Fortea, 2007, 12-13 y 154-155. Para ver el papel de los procuradores como agentes políticos y culturales, ver Martínez-Serna, 2009, 181-209. 


\section{La santidad criolla como reforma del cuerpo político}

El primer texto del que me quiero ocupar es el Memorial de las Historias del Nuevo Mundo Pirú, del franciscano Buenaventura de Salinas y Córdova, impreso en Lima en 1630. Como el título indica, este «Memorial» es un alegato, más de corte histórico-teológico y ciertamente político. ${ }^{14}$ El texto se inicia con una revisión de la historia inca y colonial temprana, para ocuparse luego de la exaltación de la ciudad de Los Reyes, como locus forjador de la santidad criolla. He señalado antes que el intento original de este documento era justificar la rápida canonización de Francisco Solano, muerto en Lima en 1610. El memorial de 1630, considerado por Raúl Porras primero y luego por Franklin Pease dentro del repertorio de crónicas historicas virreinales dada la breve revisión histórica que contiene, tuvo más bien un propósito de promoción hagiográfica y de representación politica, pues se inscribía en un conjunto de acciones de las autoridades religiosas y seculares limeñas encaminadas a elevar a la ciudad de Los Reyes al rango de civitas católica e igualarla con sus pares europeas, centros de peregrinación y devoción, lo que se había iniciado con la audaz proclamación de Solano como santo patrono de la ciudad un año antes. El Memorial de las historias del Nuevo Mundo Pirú se inscribe también en una tendencia de producción del género arbitrista religioso que ha sido destacada por Erin Rowe recientemente para el caso peninsular. Esta historiadora sostiene que la disputa sobre el patronazgo de Santa Teresa en España suscitó la producción de alrededor de cien memoriales religiosos entre 1627 y 1629 - momento culminante del debate-, todos ellos analizando la importancia de la santidad y el patronazgo en la consolidación del cuerpo político de la monarquía hispana. En otras palabras, la coyuntura era particularmente propicia al debate sobre el rol de los santos patronos en la afirmación de plataformas locales de representación y del proyecto imperial en su conjunto.

Lima no estuvo al margen de esta tendencia. Fray Buenaventura de Salinas dejó claro al final de su largo memorial de 1630 que la santidad de Francisco Solano implicaba mucho más que solo honrar una vida piadosa. Su canonización le daría a la ciudad de Lima preeminencia sobre las otras

14 Salinas, 1630. El primer memorial de fray Buenaventura de Salinas y Córdova, considerado por mucho tiempo una crónica histórica por su revisión de la historia colonial, revela aristas y contenidos de mayor complejidad cuando es leído desde varias ópticas distintas. Propongo lo mismo para interpretar otras obras de Salinas. Ver Pease, 1995, 447-448 y Gálvez-Peña, 2008, 39-75. 
ciudades del Nuevo Mundo, y la consolidaría como centro de irradiación de la evangelización entre indígenas y como locus de una acrisolada piedad castellana, elemento constitutivo de la ciudadanía española. En un segundo texto, el Memorial del P. B. de Salinas y Córdova, Procurador General de la ciudad de Lima...cuya grandeza y méritos representa a la magestad del rey nuestro señor D. Felipe IIII católico monarca en ambos mundos para que pida a su santidad la canonización de su apostólico patrón el venerable Padre Fray Francisco Solano, publicado en la corte de Madrid en 1639, Salinas elaboró los motivos teológico-políticos del memorial de 1630, en virtud de los cuales la canonización del humilde franciscano era prioridad en la política colonial. Siguiendo la línea de argumentación de Juan de Solorzano Pereyra, Salinas señaló que

los respetos y títulos de las excelencias temporales que tienen las ciudades (aunque compitan con Roma) no son de tanta consideración si se comparan con la Gloria y soberanía que alcancan por los respetos divinos de los santos que las honraron en vida y autoriza y guarda con las reliquias de su cuerpos en la muerte. Luego según desto las verdaderas excelencias de aquella ilustre ciudad y de sus reinos no deven consistir en sola su hermosura su sitio y opulencia su nobleza y cielo material sino en la Gloria y triunfo de que goza, aviéndole concedido la mano liberal de Dios entre sus astros un Nuevo sol que la alumbra, otro espíritu de Pablo, un Solano, que como viento del espíritu Santo, con ímpetu seráfico, comunicó la vida al Gentilismo. ${ }^{15}$

Es claro, como sostienen Rowe y Bartolomé Benassar, que el modelo de la santidad española era entendido como elemento cohesionador del cuerpo de la república, pero la canonización de un santo español era además visto como un canal efectivo de universalización de los logros de este modelo. ${ }^{16}$ En este texto de 1639, Salinas no solo vinculaba la santidad a la gloria de la ciudad española, sino que convertía a la santidad americana en augurio de una era dorada en la que el imperio hispano iniciaría su marcha incontenible a la conquista de los más recónditos rincones del orbe que conduciría a la reunión final de la cristiandad: Felipe IV sería el monarca universal que la iglesia reclamaba. Adicionalmente, el memorial de 1639 señaló que la pronta canonización de Francisco Solano renovaría el pacto colonial, en virtud del cual la elite de beneméritos españoles, descendientes de conquistadores y primeros colonos, perfeccionaría la evangelización indígena por medio del relanzamiento de la encomienda. Ello garantizaría

15 Salinas, 1639, 15r.

16 Bennassar, 2006, 134-135 y 146. 
la conservación y la multiplicación de la población nativa y el aumento del tributo. La pronta canonización de Solano no solo consolidaría el poder del rey en América, sino que generaría enormes caudales para el real tesoro por vía de los donativos de las elites encomenderas y por ende libraría a la monarquía católica de su crisis moral y de liderazgo. Reconocía Salinas que la renovación de la encomienda quitaría eventualmente mano de obra a la minería, pero su eclipse sería amortiguado por la expansión de la frontera agrícola y la reactivación de los impuestos y los mercados internos. Como se puede ver, era todo un proyecto de modernización asociado al patronazgo de un humilde fraile franciscano.

Fuera de ocuparse de temas no tradicionalmente hagiográficos, como el relanzamiento del proyecto imperial de los Austrias españoles, la reunión de las iglesias, la expansión de la encomienda y el aumento de la recaudación fiscal, el memorial de fray Buenaventura de 1639 enfrentó también temas relativos a la representación política. Me refiero a la discusión sobre las contribuciones económicas peruanas con las que Salinas propuso al monarca la promoción de la canonización de Solano. Para 1639 era claro que las nuevas disposiciones papales - las bulas de Urbano VIII sobre canonización de 1625 y 1634 - no favorecerían un proceso muy expeditivo como en efecto sucedió, siendo Solano beatificado en 1675 y canonizado en 1735. Para el padre Salinas, esta normativa no solo no debería ser considerada en el caso del Perú, sino que el rey tendría que solicitar al papa la exoneración de la misma por ser contraria a los intereses del reino. Para justificar la exoneración Salinas invocó temas confesionales pero también la contribución económica del reino del Perú, vista como motivo suficiente para impulsar la santidad criolla por parte de los embajadores del rey ante el papa. Si el Perú contribuía con ingentes cantidades de plata y suponía para la corona menos gasto que otros reinos de menguada fidelidad, por qué sus asuntos no podían reclamar la prioridad de los negocios reales, se preguntaba el memorialista: «No pide el Perú oro ni plata como los estados de Flandes, los presidios de Orán, las fronteras de Constantinopla y soldadesca de Italia que para todas estas partes y para el estómago de España con abundancia lo cría y con liberalidad lo embía [...] muestre el rostro de hombre y de la mano a su patrón Solano». ${ }^{17}$

La contribución económica del reino del Perú, abiertamente aludida en el memorial de 1639 como afirmación de derechos politicos, de hecho

17 Salinas, $1639,29 \mathrm{v}$. 
se había ya mencionado en el memorial de 1630 a través de veladas demandas por prebendas amparadas en la doctrina de la justicia distributiva, si bien aún no atendidas por la corona. Es el Memorial de las Historias del Nuevo Mundo Pirú el único texto peruano del siglo XVII en el que se deslizan críticas al primer ministro, el conde-duque de Olivares, cuya política de gobierno se tradujo en una mayor presión fiscal sobre los reinos americanos y en particular sobre las corporaciones religiosas. Como bien ha destacado Arrigo Amadori en su importante estudio sobre el gobierno del valido, ya desde el reinado de Felipe III se encontraba difundida en los arbitrios españoles la idea de que los reinos americanos eran una carga y no necesariamente una positiva contribución a las finanzas reales, dados sus altos costos de administración y defensa. El ya citado Fernández de Navarrete vio en América el drenaje de los mejores recursos humanos de la península debido a la migración. En 1630, fray Buenaventura de Salinas no se quedó callado e interpeló al primer ministro, acusándolo de ser una mala influencia para la persona real, lo que era evidente en la negligente gestión de los problemas peruanos, desde una canonización que no se producía hasta las mercedes y exenciones debidas a la postergada elite encomendera. Afirmando la postura de denuncia de la nueva tradición arbitrista religiosa, informada de anti-maquiavelismo, señaló Salinas que

\begin{abstract}
para que así llegassen a saber y remediarse cosas que tanto importan a su corona real, y tanto las encubren interessados enemigos de su Gloria y monarquía, sin reparar que el Rey, que duerme, o se echa a dormir, descuydado con los que le assisten, es sueño $\tan$ malo, que la muerte no lo quiere por hermano, y le niega el parentesco, deudo tiene con la perdición y el infierno. Reinar es velar. Quien duerme no reina (dixo otra voz mas valiente que la mia), y rey que cierra los ojos, da la guarda de sus ovejas a los lobos. Y el ministro que guarda el sueño del rey, lo entierra vivo, no le sirve, porque lo infama; no le descansa, porque cuando le guarda el sueño, le pierde la honra y la conciencia: y estas dos cosas traen apresurada su penitencia, con la ruina, y desolación de los reinos. Rey, que duerme... govierna entre sueños, y quando mexor le va, sueña que govierna. De modorras y letargos de príncipes adolecieron muchas repúblicas y grandes monarquías se acabaron. ${ }^{18}$
\end{abstract}

Es difícil determinar si este arrojo fuera conocido o leído en la corte y por quiénes, pero hay evidencia de que fray Buenaventura de Salinas quiso hacer conocer este memorial en Madrid. En todo caso, nadie antes que él se había atrevido a semejante libertad, iniciando un tono de discusión y disenso importante para los intereses de sus pares religiosos y criollos del

18 Salinas, 1630, 297. 
Perú. ${ }^{19}$ Los memoriales de Salinas cumplieron además una función muy importante, cual fue la difusión y la re-elaboración de las ideas vertidas en las hojas de populares arbitrios peruanos que los antecedieron, con lo que se prueba que el arbitrio religioso se inspiró en debates no necesariamente vinculados a los temas de preocupación para la iglesia, pero que se adaptó a sus necesidades dos décadas después. Me refiero a la deuda de fray Buenaventura con la obra del licenciado Juan Ortiz de Cervantes, quien como procurador de los encomenderos del Perú compuso tres arbitrios impresos entre 1619 y 1620: el Memorial que presenta a Su Magestad el licenciado Iuan Ortiz de Ceruantes, abogado, y procurador general del Reyno del Pirú, y encomenderos sobre pedir remedio del daño, y diminución de los Indios, y propone ser medio eficaz la perpetuydad de encomiendas: presenta el parecer de los juezes comissarios, que fueron à aquel reyno à tratar de la perpetuydad (Madrid, 1619); el Parabién al Rey D. Felipe III Nuestro Señor que da la cabeca del reyno del Perú en su nombre el licenciado Juan Ortiz de Cervantes su Procurador General en la Corte (Madrid, 1620), y, finalmente, la Información en favor del Derecho que tienen los nacidos en las Indias a ser preferidos en las prelacías, Dignidades, Canongías y otros beneficios eclesiásticos y oficios seculares dellas (Madrid, 1620). Los temas centrales en todos estos textos fueron la perpetuidad de la encomienda, el aumento de la población indígena, el incremento del tributo y la formalización de la justicia distributiva como política de gobierno de las Indias y como canal de afirmación del pacto colonial. Todos estos temas fueron tomados en cuenta por Salinas en 1630 y 1639, articulando estas ideas alrededor de un nuevo eje teológico político que fueron la canonización de Solano y las demandas de representación de la elite criolla.

No estuvo solo fray Buenaventura de Salinas en los esfuerzos por demostrar que los voceros de las órdenes religiosas eran los llamados a alertar a la corona de los peligros del mal gobierno y, al mismo tiempo, los encargados de negociar los privilegios de sus pares sociales en el virreinato del Perú. Veinte años después del segundo memorial de Salinas, otro documento de enorme importancia para entender el género memorialista vio la luz en Madrid. Se trató del Informe a Nuestro Padre General de la Orden de Predicadores, Fray Joan Baptista de Marinis, le ofrece el presentado Fray Antonio González de Acuña, catedrático de Prima de Moral,

19 Gálvez-Peña, 2008. 
Procurador de la Real Universidad de los Reyes, definidor de la Provincia de San Joan Baptista del Perú (Madrid 1659), de fray Antonio González de Acuña, noble dominico limeño y procurador de la provincia peruana en las cortes real y pontificia. A juzgar por el título, este memorial aparentaría no serlo en el sentido de arbitrio religioso que hemos visto, sino tan solo tratarse de un mero informe del procurador de la provincia peruana al general de la orden. Empero, la lectura y el análisis del mismo revelan un documento de mayor trascendencia y profundidad temática, y a su autor como a un arbitrista nato identificado con las causas de las corporaciones religiosas y la elite criolla.

El objetivo del viaje de fray Antonio a Roma era promover la canonización de Rosa de Santa María y de fray Juan Masias, o sea que en ese sentido el Informe compartía el tema de la santidad criolla con los textos del padre Salinas. Pero la diferencia se encuentra en la argumentación, pues González de Acuña partió de la premisa de que la donación pontificia a la corona española era la razón para justificar cualquier apoyo a las causas religiosas en el Perú. Si los reyes de Espana habían sido beneficiados con los reinos de Indias por el vicario de Cristo, esto se debía a la necesidad de expandir la fe católica por todo el orbe. La santidad de los candidatos dominicos del Perú solo coadyuvaría a las buenas obras de la orden y a la causa toda de la iglesia militante, y esa precisamente era la misión política de la casa de Austria. El apoyo a las órdenes y a la santidad criolla serían no solo logros confesionales y políticos, sino el mejor escudo contra los ataques extranjeros a la monarquía católica. En este sentido, es necesario recordar que el Informe aparece en un contexto europeo poco propicio a la celebración de las glorias imperiales españolas y al reconocimiento de la legitimidad de la posesión de sus dominios. La paz de Westfalia de 1648 había reducido el poder de Espana en el mundo y la multiplicación de ediciones de la Brevísima Historia de las Destrucción de las Indias de fray Bartolomé de las Casas era creciente - en particular durante la segunda mitad del siglo-, con lo que el memorial del dominico peruano buscó consolidar la genealogía de la legitimidad de la posesión de las Indias. En palabras de fray Antonio: «Los reyes de España no posseen las Indias por codicia como lo prueba la conversión de gentiles, las órdenes fundadas, las ciudades construidas, las universidades [...] y así también la preocupación de los Indios». ${ }^{20}$ La posesión de las Indias estaba

20 González de Acuña, 1659, 20r. 
además bien justificada en los frutos de la iglesia peruana, que agradecida de los favores de su rey contribuía a su gloria y demostraba fidelidad formando mártires, autoridades, arzobispos y catedráticos. El Perú era, pese a su lejanía de la metrópoli, leal a la corona y ello se debía a los logros de las órdenes, en particular a la de Santo Domingo. A diferencia de otros reinos de la monarquía compuesta, cercanos al rey pero desobedientes, el reino peruano destacaba en su fidelidad, contribuciones y valores hispanos: «Y si con atención se advierte, que los fueros de la soberanía y obligación del vassallaje tan natural que no a avido nación bárbara que no la reconozca son que al rey porque trabaja para todos se le debe sustento, porque es señor, reconocimiento, porque influye en todas las comunicaciones civiles se le debe parte, obediencia porque govierna, temor porque castiga, porque premia honor y fuerças porque defiende: conocerá lo que obraron nuestros religiosos sirviéndole en el Perú a imitación de sus primeros padres». ${ }^{21}$

Fray Antonio González de Acuña tampoco se alejó del anti-maquiavelismo en sus recomendaciones de buen gobierno para el príncipe cristiano. España había ya pasado por muchas crisis para dejar en manos del ministro de turno, y en particular de aquellos no afectos a la obra de la iglesia, los asuntos verdaderamente importantes en la afirmación de la soberanía del rey y de sus deberes ante Dios, a quien además debía la posesión de sus principales dominios. El mejor gobierno era entonces aquel en el que la justicia del monarca, la relación directa con los súbditos, era manifiesta. Como bien señaló fray Antonio, un rey podía estar animado de buenas intenciones pero erraba si el gobierno quedaba exclusivamente en manos del servidor: «la execución peligra del ministro, a quien toca: no es culpable la Majestad en lo involuntario, para unir lo distante: es forzoso el medio y siéndolo el que govierna, si estravía la voluntad del príncipe, le ofende el que obra mal, usando del poder para la tiranía, a Dios irrita, enoja al rey [...] qualquiera gemido indiano altera la quietud de nuestro rey». ${ }^{22}$ Es claro que González de Acuña afirmaba de esta manera la necesidad de una mayor atención al Perú, un reposicionamiento en términos de la representación y el reconocimiento de los derechos de los súbditos lejanos y desatendidos. La corona lo sabía, solo tenía que atender las demandas de las corporaciones religiosas y de las elites beneméri-

21 Ibidem, 162v.

22 Ibidem, 20v. 
tas, porque de no hacerlo enfrentaba riesgos: «La fidelidad del vassallo respira en el aliento del rey...». ${ }^{23}$

El Informe de González de Acuña al padre general de los dominicos, impreso en la corte real, no pudo haber tenido un mensaje más claro respecto de la influencia que muestra del anti-maquiavelismo, evidente desde la simbología misma del frontispicio. González de Acuña hizo muy claras sus intenciones de reposicionar a la iglesia corporativa peruana al interior de la monarquía y el imperio. Las dos columnas de Hércules, representación de la monarquía española, se encuentran coronadas nada menos que por el escudo de la ciudad de Los Reyes y por el perro fiel, símbolo de la orden de Santo Domingo. De este modo se reproduce ese orden político que proponía Giovanni Botero en La grandeza de las ciudades, en el cual ciudad y religión dejaban evidencia de la «prudencia y razón de estado» que atendiendo a la razón divina como principio director, mantenían a los súbditos en leal obediencia a su rey y al reino feliz. No había — en palabras del teórico italiano - mejor fomento para la riqueza y la prosperidad de una ciudad que la posesión de una famosa reliquia, la asistencia divina y la autoridad ejemplar en el gobierno eclesiástico. ${ }^{24} \mathrm{El}$ memorial de fray Antonio puso en palabras, casi al final del texto, el mensaje tipológico de su portada - la tradición de leer eventos contemporáneos como la realización de una profecía de sino religioso- en una exaltada arenga que parece estar más bien dirigida al rey que no al superior de los dominicos en Roma. ${ }^{25}$ El programa de gobierno de la católica ciudad de Los Reyes del Perú y sus cuadros de funcionarios sagrados, llamados a ser los nuevos baluartes de un orden imperial:

Oh Rey... Goza edades sin término la possesión de coronas, que el sudor, la lealtad, el valor de tus vasallos pusieron por despojo a tus pies y se ve por adorno en tu cabeça. No la emulación pueda assechar lo grande, que la envidia mayor muere en si misma: vive, y vivan a pares los que han de perpetuar tu vida, para que en gloriosa sucesión España triunfe Reino, las Indias se miren imperio y Emperador, y Rey obediente a la Iglesia, patrón a tus señoríos, açote seas a los extraños. ${ }^{26}$

23 Ibidem, 184r.

24 Botero, 2013, 36.

25 Sobre el mensaje providencialista y teórico de las tipologías en publicaciones de la temprana era moderna ver el sugerente trabajo de Cañizares-Esguerra, 2009, 237-263.

26 González de Acuña, 1659, 176v. y 177r. 


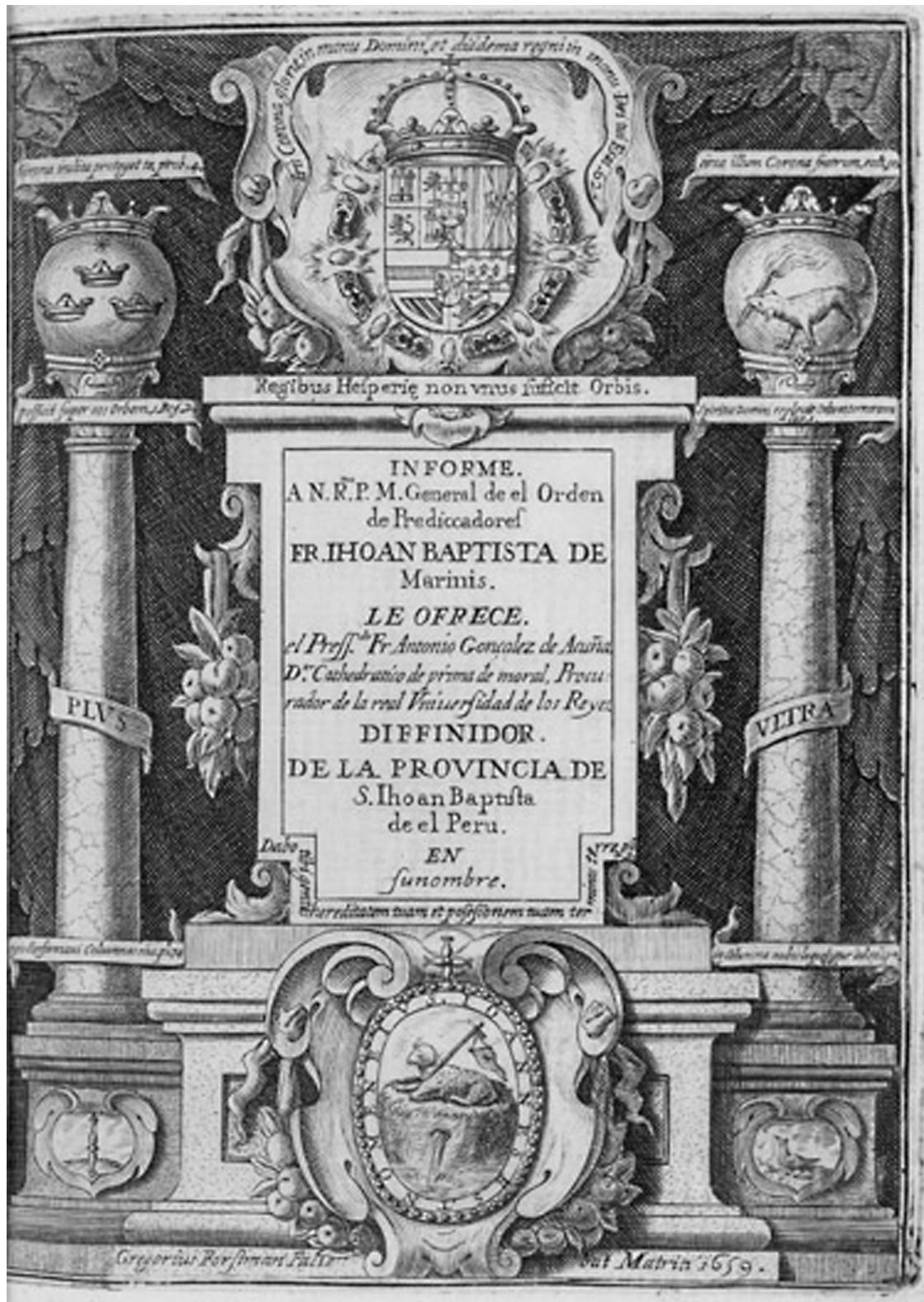

Frontispicio del Informe de fray Antonio González de Acuña (Madrid, 1659). Original en la John Carter Brown Library (Providence). 


\section{El memorial desde el púlpito}

Si el arbitrio/memorial merece una revisión para enfatizar su contenido religioso, no menos sorpresas nos depara el estudio del sermón como fuente para el conocimiento de la problemática política virreinal. Con una trayectoria relativamente corta, los estudios sobre prédica sagrada y política han sido radicalmente renovados. Magdalena Chocano consideró el sermón como fuente para entender las demandas de las corporaciones comerciales en su libro sobre la producción escrita mexicana del siglo XVII. La prédica novohispana colonial se ha enriquecido mucho con los recientes trabajos de Perla Chinchilla y Carlos Herrejón, quienes han definido aún más el corpus de los siglos XVII y XVIII analizando la producción y el impacto del discurso homilético. Scott Eastman, por su parte, ha resaltado la intersección entre sermón y nacionalismo en el Atlántico español entre fines del siglo XVIII y la coyuntura independentista, revelando la riqueza del género y la complejidad de su contenido. Si bien conocemos más sobre el sermón como fuente de ideas políticas y culturales en el temprano período moderno, es aún poco lo que sabemos para el Perú y, en particular, respecto de su intersección con el género del memorial. ${ }^{27}$

La primera afirmación que se desprende de las fechas y la existencia de sermones en repositorios peruanos y extranjeros, es que pareciera que el arbitrio religioso peruano declina en la segunda mitad del siglo XVII, precisamente cuando más bien el sermón repunta. Hacia el final del reinado de Felipe IV, el sermón abunda y se desarrolla mucho en el virreinato del Perú, mientras que el memorial de González de Acuña sería el canto de cisne del género. De hecho, esto se va anunciando desde la década de 1630, cuando se advierte una creciente politización del contenido del sermón, lo que me lleva a ver en este fenómeno un intento de reemplazo del antiguo memorial por una versión más corta, más apasionada, pero con la misma importancia como literatura de negociación con la corona. El sermón político se alimenta del memorial de alguna manera. Ilustraré este fenómeno con el caso sumamente interesante del proceso de conversión de un sermón jesuita en memorial, ocurrido en Lima en 1644. Me refiero al Discurso del mejor arbitrio de Philipo IIII el grande rey de las Españas y emperador de las

27 Para el final del período virreinal ver Eastmann, 2012 y Gálvez-Peña, 2012a. Para el siglo XVII se puede consultar el trabajo ya citado de Chocano, 2000. De los varios estudios de Perla Chinchilla me referiré sólo a uno de sus primeros artículos sobre el tema: Chinchilla, 1996. Asimismo, Herrejón, 2003. 
Indias. Elección de María Santísima Señora Nuestra por patrona de su Española monarchía, del jesuita limeño Gregorio López de Aguilar. La declaración del patronazgo de la Virgen para las armas de España fue la ocasión celebrada solemnemente por el virrey marqués de Mancera, quien encargó al padre López de Aguilar la lectura del sermón primero y la publicación más tarde el mismo año. La edición del sermón original devino, sin embargo, en un producto distinto que remite a la era de los memoriales. Justificó el predicador su empresa enfatizando el hecho de que fuera el arbitrio religioso el mejor formato de comunicación del original mensaje de su sermón: «Señor Illustrísimo: muchos arbitrios han dado estos días los doctíssimos, espiritualíssimos y fervorosíssimos padres predicadores para el remedio de las necesidades públicas y conservación destos reynos en nuestra posesión». ${ }^{28}$

Se hace claro desde la dedicatoria del sermón/arbitrio que el jesuita estaba interesado en discutir sobre la crisis que afectaba al cuerpo de la república. Las calamidades públicas fueron vistas como originarias en el pecado colectivo y solo podían ser remediadas mediante la devoción y la revitalización del vínculo entre la iglesia y el estado. El arbitrio del padre López de Aguilar utilizó como premisa argumentativa aquello de que todo remedio a la calamidad pública pasaba por la primera razón de estado del anti-maquiavelismo, cual era la obediencia a la corona pues, se preguntaba este autor: ¿qué reino podría construirse con solidez sobre la desobediencia? Felipe IV, como Jesús en el calvario, enfrentaba la rebelión de Portugal, Cataluña y Flandes contra su dominio, y esa crisis política era causada por el desconocimiento del vasallaje: «¿No está allí esse rey negado de unos malévolos vassallos que por una sin razón de estado rehúsan y desechan el suave yugo de su real dominio queriendo más ser señorieados de tyranos intrusos reyes? $\gg^{29}$

La religión de la mano de los príncipes era cura cierta para toda crisis, en particular las políticas. Pese a los «infelices [...] sucessos de nuestra monarchía y muchos los reynos que se han dividido della por rebeliones y guerras [...] es María de poderosa y Philipo el grande de gran devoto hijo suyo [que] podemos asegurar que ni las pérdidas tienen otro remedio ni lo entero otra conservación sino esta virgen al pie de la cruz». ${ }^{30} \mathrm{El}$ centro de esa religiosidad hispana que soportaría el trono sería la devoción

28 López de Aguilar, 1644, 2v.

29 Ibidem, $3 \mathrm{r}$.

30 Ibidem, $4 \mathrm{r}$. 
mariana, tan favorecida por la corona de España desde tiempos de Felipe II; la mejor curación de la monarquía y la república. Dado que el fuerte tono moral del arbitrio responde en parte a la lógica moralizadora del sermón original, no sorprende que el padre López de Aguilar se refiera a la crisis tanto como una situación política como a una relajación de costumbres, cuya frivolidad no pierde oportunidad de condenar. Opuesta a la pureza mariana se presentan el lujo, el consumo y los usos de la vida cortesana de Lima, que en opinión del jesuita eran particularmente manifiestos en el gusto por la comedia, de graves consecuencias para la moral femenina. No ahondaré en una lectura desde la perspectiva del género o la historia de la sexualidad, pero es ciertamente interesante esta relación entre teatro y relajación de costumbres femeninas, que evidencia la multiplicidad de mensajes del memorial: «tanto tablaje autorizado en casas de poderosos donde se pierde el tiempo, la plata y la conciencia, tanta farsa y representación y comedia impúdica donde la honesta casada y la sencilla doncella tienen escuela pública para aprender el arte de amar y ser amadas y las metaphysicas del amor laçibo». ${ }^{31}$

Precisamente será en el terreno de la metafísica donde destaque el análisis político del padre López de Aguilar para conceptualizar la crisis política del imperio. El patrocinio de la Virgen a la nación española llevará al arbitrista a hacer un repaso de la situación europea en la convulsa década de 1640 y a comparar la vapuleada monarquía compuesta con la túnica inconsútil de Cristo, a fin de entender la crisis de la relación entre reinos y corona. Dijo el jesuita:

La vestidura, la real púrpura de Phillipo el grande se estiende a todas quatro partes del orbe, pues en todas ellas tiene reynos o provincias o ciudades en Europa, Africa, Asia y América, con naciones de todas ellas adornó magestuosamente Dios a tan gran monarcha... mas ay dolor, ay triste caso, que de raigones han hecho rebeldes o invidiosas armas en esta púrpura, todas originadas de contiendas de jurisdiciones entre parientes, hermanos y cuñados. Allá le llevó en Perpiñán un girón el cuñado francés émulo perpetuo de su Gloria. Allá desmembró otro pedaço el inobediente catalán vidrioso conservador de sus presumidos fueros. Allá dividió otra pieça el pariente duque portugués disgustoso siempre en su devida sugeción. Acullá en la India cogió su retaço el astuto visorrey pescador ganancioso a la rebolución destas aguas. Acá en el Brasil echó mano a una tira el rebelde olandés, cerviz siempre indómita al yugo de su señor natural. ¿Qué es esto españoles? En verdad que no ha sido nuestro reino túnica inconsútil de nuestro gran Rey. ${ }^{32}$

31 Ibidem, ff. 7r. y 7v.

32 Ibidem, f. $7 \mathrm{v}$. 
La característica de ser inconsútil la túnica de Cristo — del latín inconsutilis, es decir hecha sin costura, de una sola pieza-, sirve de perfecta metáfora política para explicar la naturaleza sacramental de la monarquía católica bajo Felipe IV; al menos así lo era en la imaginación política de López de Aguilar y de otros arbitristas después de él. En todo caso, queda claro que los teóricos de las órdenes religiosas entendían que se debía a las pugnas internas en la monarquía compuesta y a la crisis de obediencia al rey el rasgado de esa túnica de naturaleza inconsútil que era el cuerpo político de la monarquía española. ${ }^{33}$ No todo está perdido recordó el arbitrista, pues si había reinos que se perdían por la acción humana, era porque al fin y al cabo habían llegado a formar parte de la corona española por vía humana. Empero, aquellos reinos que los reyes católicos obtenían por gracia divina, esos sí que eran de naturaleza inconsútil, dada la relación cuasi sacramental entre soberanos y vasallos, sancionada por Dios. Estos vasallos jamás perderían la fe que los mantenía unidos a su soberano:

La Quarta parte del mundo es la América, su principal reyno el Perú, su corte y cabeça antes de agora en tiempo de sus Reyes fue el Cuzco, pues a essa ciudad vino poco más de cien años ha entregar este imperio a los españoles [...] María y la Cruz conduxeron los españoles al descubrimiento, conquista bélica y possessión justificada deste imperio peruano que estriva en su protección [...] Luego a sombra de María junto a la cruz es evidente la justificada possessión que goça nuestra nación y cathólico monarca deste Nuevo mundo. Que es el argumento del erudito Justo Lipsio en sus libros de la Virgen Hallense. ${ }^{34}$

Es particularmente interesante que López de Aguilar construyera su interpretación de la conquista del Perú a partir de la obra del tratadista flamenco Justus Lipsius o Joest Lips (1547-1606), que es posterior a este hecho histórico, pero que le permitió fundamentar esa alianza simbólica y política entre la corona española y el virreinato peruano a partir del culto mariano. Asimismo, se sirvió de ese mito teológico-político para validar a los beneméritos, descendientes de los conquistadores. Lipsio, cabe recordar, fue uno de los principales exponentes del antimaquiavelismo católico al servicio del naciente imperio hispano y su obra Los milagros de Nuestra Señora de la Consolación de Halle, impresa por primera vez en 1603,

33 En un sermón limeño de 1679, el padre Bernardo de Mispilívar, manejaba ya la metáfora de la túnica inconsútil en el sentido que le dio López de Aguilar y lo hacía dentro de un sermón-arbitrio: «Cómo assegurar la consistencia de nuestra Española Monarquía en los mismos medios de este gran arbitrio, aquel hombre a quien le cupo en suerte la túnica inconsútil?» Mispilívar, 1679, 11r.

34 Ibidem, 19r. y $21 \mathrm{v}$. 
devino en pieza angular del arbitrismo religioso peruano del siglo XVII. Para Lipsio, la relación entre el trono y el altar era necesaria a fin de afirmar la cohesión pacífica de la monarquía compuesta. Sin embargo, como flamenco que vivió en medio de una guerra de independencia, nunca se pronunció en Virgo Hallensis sobre la naturaleza del vínculo vasallático del Flandes español. Reinterpretando a Lipsio, la inconsutilidad del imperio de Felipe IV para López de Aguilar solo sería posible con un relanzamiento del Real Patronato y del pacto colonial, en el cual la iglesia peruana serviría mayores propósitos de política imperial trabajando en la consolidación de la obediencia de los reinos entregados por la Providencia al monarca católico. A su vez el rey, en atención a tan leales súbditos que le habían sido entregados por Dios, y no por legados dinásticos o guerras de conquista, favorecería la obediencia peruana con una justicia real, hecha a la medida:

entiendan todos, principalmente los príncipes en lo secular y lo eclesiástico que este don por más milagroso que sea y de mano de María, será con arrepentimiento si no executásemos el fin y los títulos por los quales nos fue dado y poseemos este Nuevo Mundo. ¡O qué punto tan digno de ser oydo con atención! Lo cierto es que ni por cláusula del testamento de Adam ni por derecho natural hereditario, ni por voluntaria elección de los Américos, es nuestro cathólico monarca emperador de las Indias. Pero por autoridad mayor que es elección divina amparada por María y confirmada por la silla apostólica. Y los títulos del dominio, posesión y usufructo de los thesoros peruanos no son otros sino la publicación y ampliación de la ley evangélica, la conversión de los indios al conocimiento y adoración de Christo, la enseñança para que dexen la idolatría [...] la provisión de ministros evangélicos que los instruyan en los misterios de la Fe $[\ldots]$ assí lo reza expresamente la bulla de Alejandro VI. ${ }^{35}$

Así, el reposicionamiento del virreinato del Perú en un nuevo orden político confesional, donde las más leales posesiones de la casa de Austria soportaban la gloria de la monarquía, cumplía con el mandato providencial y las expectativas de la elite criolla limeña, en particular aquella que operaba desde la trinchera de la iglesia corporativa. Hay tangencialmente un endose a los beneméritos, a quienes se les incluye en un plan divino, en el que la Virgen María decidió que el Perú fuera dominio del rey de España. Para entender este renovado pacto entre monarca y tan leales vasallos españoles al otro lado del Atlántico, López de Aguilar propuso examinar las funciones de la corona a la luz de una nueva interpretación de las bulas alejandrinas, retomadas como documentos fundacionales del pacto colonial.

35 López de Aguilar, 1644, 27r. 
En esta línea de redefinir el rol político de las bulas papales casi al final de la guerra de los Treinta Años, López de Aguilar se alineó con las ideas de su hermano de orden, Diego de Avendaño, quien propuso similar idea en su Thesaurus Indicus, otro tratado con ribetes de memorial, publicado en Lima en $1668 .{ }^{36}$ En este relanzamiento imperial de signo jesuita, la iglesia - atacada como origen de los problemas unas décadas antes- ofrecía no solo la posibilidad de conectar el trono y el altar en un proyecto político providencial, sino que al hacerlo el monarca abandonaba posturas nefastas originadas por las de malas influencias y se repotenciaba el cuerpo místico de la monarquía. En palabras del padre López de Aguilar, «los malos ministros del rey no cessaban de atizar el fuego... en que se abraçen los príncipes. Pero estos... trocando el horno en confessionarios reconocen la tribulación por efecto de culpa». ${ }^{37}$ Es decir, los confesores serían siempre mejores ministros que los validos.

Finalmente, quiero destacar un aspecto muy original del sermón-arbitrio del padre López de Aguilar, que es la noción de un estado central de signo religioso que se anuncia en esa reverenciada «túnica inconsútil» de Felipe IV. Como bien ha señalado John Elliott, no siempre se pensó en la monarquía compuesta como el ideal de sistema político en el temprano período moderno, aunque fue casi la norma en la Europa de los siglos XV al XVII. Los monarcas gobernaron sobre monarquías compuestas haciendo uso del principio jurídico del aeque principaliter, que Juan de Solórzano definiera como la unión de reinos bajo una misma corona donde el rey, respetando los fueros de los distintos reinos, reinaba de manera individual. ${ }^{38}$ En el caso español, a lo largo del siglo XVII las pugnas por mayores demandas de representación entre la corona y las elites locales revelaron las fisuras y las críticas al modelo. Como vimos antes, los reinos indianos trataron de asegurar una cuota de representación, a veces con una venal aquiescencia de la corona — urgida de apoyo financiero- y a veces con objeciones. Desde mediados de la década de 1620 y durante la siguiente, el conde-duque de Olivares, buscó la mayor centralización de la funciones de la monarquía en detrimento de los derechos de representación y de los fueros autonómicos, en particular de los reinos indianos, como ha destacado Arrigo Amadori en su reciente estudio sobre el gobierno del valido. ${ }^{39}$ Los

36 Avendaño, 2001, caps. I, V, VI y VII.

37 López de Aguilar, 1644, 27v.

38 Elliott, 2009, 6.

39 Amadori, 2013, 462. 
reinos de Indias, jóvenes en términos de creación política, llegaron tarde a negociar cuotas de representación, aunque hicieron bastante por lograrlas a través de sus elites y sus procuradores, en particular los religiosos. Hacia mediados del siglo XVII, al estar esta negociación exclusivamente en manos de los representantes de la iglesia, la agenda representativa de las elites quedó subsumida en aquella de las órdenes y acaso hasta diluida.

Sobre el modelo de imperio que la iglesia criolla peruana quería, vale la pena distinguir etapas y diferencias. Los memoriales de los padres Salinas y Gónzalez de Acuña apelaron a un mayor empoderamiento de las órdenes religiosas pero también de las elites políticas, y esta característica no está presente en el sermón arbitrio de López de Aguilar y, en general, en la producción intelectual de la provincia peruana de la Compañía de Jesús. Cabría preguntarse si los jesuitas criollos de Lima se estaban decantando por la opción de una monarquía central fuerte de acuerdo al modelo lipsiano; modelo que les costaría precisamente su autonomía un siglo después. Por ejemplo, en la obra de Diego de Avendaño ya citada, el tratadista no defendió a los encomenderos como Salinas lo hiciera en la década de 1630. Su visión de la justicia distributiva era una donde el rey tenía irrestricto control de sus actos, incluso de aquellos concernientes a su magnanimidad. Sin embargo, el padre Avendaño tampocó entregó al monarca un poder absoluto. Por el contrario, la donación papal subordinaba en parte al rey de España a esos magistrados de lo sagrado que eran los burócratas religiosos y los misioneros, para los que se requería la generosidad de la corona. ${ }^{40}$ Este fortalecimiento del poder real ya está presente en el arbitrio de López de Aguilar, quien al condenar a los vasallos desleales de 1640 propuso una monarquía central donde la lealtad política se identificara con la religión, como quería Lipsio a fin de cohesionar el fragmentado Flandes y repotenciar la monarquía católica. ${ }^{41}$ El imperio hispano —en 1644 — ofrecía para los teóricos jesuitas la posibilidad de una real, no retaceada, y central autoridad real. Buscaron un modelo de estado que prestara mayor atención a las demandas de las órdenes y a la iglesia criolla peruana en particular, que era una forma distinta de presionar por derechos de representación de las elites, respecto de lo que se advierte en las propuestas franciscana y dominica, antes comentadas.

40 Avendaño, 2001, título II.

41 Elliott, 2009, 16. 


\section{Conclusiones}

He querido con estos ejemplos renovar la visión de un género que se pensaba exclusivamente ligado a los temas jurídicos. Una perspectiva más amplia del contenido de arbitrios y memoriales que explore sus conexiones con lo teológico y lo político permitirá también considerar relaciones históricas y sermones como parte de la tradición memorialista/arbitrista. Ahora bien, no es casual que los arbitrios y memoriales se fusionaran con otros géneros precisamente cuando el sistema de procuradores se vio restringido de operar y las órdenes religiosas en el Perú - y todas las corporaciones económicamente relevantes junto con ellas- experimentaran crecientes presiones fiscales. ${ }^{42}$ El fiscalismo real se inició en el reinado de Felipe III pero llegó a su clímax en el valimiento del conde-duque de Olivares y fue de hecho el más exitoso programa fiscal del reinado de Felipe IV, pero en particular en el período que va de 1621 a 1643. Las distintas corporaciones en el Perú tuvieron que renegociar sus espacios de representación y sus prerrogativas, lo que se evidenció en la venta de oficios, la prórroga en el goce de encomiendas, las composiciones de tierras, los asientos con los tribunales del consulado y, en particular, la expansión y el empoderamiento de las órdenes religiosas. ${ }^{43}$ Cuando las restricciones a los procuradores seculares evidenciaron que la corona no promovería mayor espacio de negociación para las élites politicas y económicas peruanas, fue el lobbysmo de los representantes de las corporaciones religiosas el que tuvo a su cargo, si bien de manera tangencial, atender a los reclamos de beneméritos. En este proceso de negociacion transatlántica, los procuradores religiosos del Perú redefinieron también el género del arbitrio/memorial según formatos propios del discurso religioso.

El memorialismo religioso, activo desde la década de 1630, reemplazó progresivamente las demandas de los encomenderos de la década anterior y consolidó en unos veinte años un género histórico-religioso que, nutrido de la doctrina anti-maquiavélica, discutió nuevos horizontes para el pacto colonial y hasta una redefinición de la institución del real patronato, revisando asimismo la historia colonial temprana a fin de reposicionar a la iglesia peruana en la fundación del imperio. La posibilidad de consolidar un estado confesional suponía redefinir a la monarquía compuesta y ligar-

42 Ibidem, 183.

43 Amadori, 2013, 461-462, 464. 
la más a las Indias y menos al escenario europeo. Este proyecto fue entendido en Lima como la ansiada oportunidad para el empoderamiento de la iglesia corporativa y del grupo social al que los intelectuales religiosos pertenecieron por origen. El arbitrismo religioso limeño del siglo XVII pretendió una corona con mayor poder de negociación ante Roma a fin de privilegiar una iglesia peruana acaso más autónoma y ciertamente vinculada a las agendas de afirmación de la conciencia local criolla, como la santidad y la redefinición del pacto colonial. Sin embargo, dentro del memorialismo religioso peruano debemos ver tendencias y momentos. La Compañía de Jesús no se involucró tanto con las reivindicaciones de las elites sociales y políticas virreinales como sí parece haber sido el caso de franciscanos y dominicos, y hasta llegó a proponer un modelo anti-maquiavélico de monarquía central que anunciaba el ocaso de las monarquías compuestas. ${ }^{44}$ La iglesia corporativa peruana creó en su discurso memorialista de mediados del siglo XVII su propia ciencia de la politica cristiana pero solo tuvo dos o acaso tres décadas para hacer sus propuestas. Como bien ha sugerido Heinz Schilling - a quien debemos las reflexiones más interesantes para entender el rol de la religión en los imperios de la temprana era moderna y su indirecta influencia en la construcción de la modernidad- la creatividad y la agencia política de los intelectuales religiosos de este período es crucial para entender el desarrollo del estado al menos hasta 1650. Pero ese diálogo con la corona fue breve y accidentado y, por ende, determinó el escaso éxito del arbitrismo religioso.

Los arbitristas religiosos peruanos se concibieron a sí mismos como una burocracia suficientemente capaz y entrenada para dirigir la nave imperial de la monarquía católica, pero, además de sus objetivos confesionales, asumieron el papel de voceros de las demandas regionales de sus pares sociales, pues las entendieron perfectamente imbricadas y útiles a la salud del cuerpo místico de la monarquía católica de España. Además de sus facultades como promotores de causas de canonización, el padre Salinas se presentó como procurador de la ciudad de Los Reyes y el padre González de Acuña como procurador de la universidad; el padre López de Aguilar quería ser confesor y consejero político. En palabras de Schilling, los agentes de la confesionalización buscaron la «cristianización» de la sociedad, imponiendo a vasallos y príncipes la obligación de la auto-exploración y la auto-guía, la introspección y el deber moral, valores positivos y necesarios

44 Schilling, 2008, 14-15. 
para fortalecimiento del cuerpo de la república en un tiempo de crisis. ${ }^{45} \mathrm{La}$ modernidad de los arbitristas religiosos peruanos radicó en pretender reorientar el gobierno secular según principios rectores que buscaban la resacralización de la sociedad y también la renovación del estado, pues estos principios no se oponían. Si este discurso enfrentó la oposición de Olivares primero, se enfrentó luego a la debacle política de la nefasta década de 1640. A partir del reinado de Carlos II, el arbitrismo religioso peruano - como el paradigma de la confesionalización en general- perdió impulso, pues la promesa de un orden católico global renovado bajo el cetro de los Austrias de España no tenía ya referentes de realidad y la secularización del estado moderno europeo se afianzaba. Al menos entre 1630 y el final del reinado de Felipe IV, existió una ventana de oportunidad para imaginar desde Lima una recomposición de la monarquía católica con un repotenciado rol de las elites religiosas del virreinato del Perú en ella, y el arbitrismo/memorialismo religioso expresó tal visión del imperio.

Recibido el 31 de enero de 2014

Aceptado el 6 de abril de 2014

\section{Bibliografia}

Amadori, Arrigo: Negociando la obediencia. Gestión y reforma de los virreinatos americanos en tiempos del conde-duque de Olivares (1621-1643), Madrid, CSIC, Universidad de Sevilla y Diputación de Sevilla, 2013.

Avendaño, Diego de: Thesaurus Indicus, edición de Angel Muñoz García, Pamplona, Ediciones Universidad de Navarra, 2001.

Benassar, Bartolomé: La monarquía española de los Austrias. Conceptos, poderes y expresiones sociales, Salamanca, Universidad de Salamanca, 2006.

Botero Giovanni: On the Causes of the Greatness and Magnificence of Cities, Buffalo, Londres y Toronto, University of Toronto Press, 2013.

Cañizares-Esguerra, Jorge: «Typology in the Atlantic World. Early Modern Readings of Colonization», en Baylin, Bernard y Denault, Patricia L. (eds.), Soundings in Atlantic History, Latent Structures and Intellectual Currents, 1500-1830, Cambridge y Londres, Harvard University Press, 2009.

Chinchilla, Perla: «La prédica de las pasiones. La predicación en el siglo XVII», Historia y Grafía, 7, México, 1996, 97-124.

Chocano Mena, Magdalena: La fortaleza docta. Elite letrada y dominación social en México colonial. Siglos XVI y XVII, Barcelona, Edicions Bellaterra, 2000.

45 Schilling, 2008, 26. 
Eastmann, Scott: Preaching Spanish Nationalism across the Hispanic Atlantic, 1759-1823, Baton Rouge, Louisiana State University Press, 2012.

Elliott, John: Spain, Europe and the Wider World, 1500-1800, New Haven y Londres, Yale University Press, 2009.

Gálvez-Peña, Carlos: «El carro de Ezequiel. La monarquía hispana de fray Buenaventura de Salinas y Córdova». Histórica, XXXII-1, Lima, 2008, 39-75.

Gálvez-Peña, Carlos: «El rey, la constitución y la patria. Prédica y cultura política en el Perú durante la primera mitad del siglo XIX», en Mc Evoy, Carmen; Novoa, Mauricio y Palti, Elías (eds.), En el Nudo del Imperio. Los Orígenes de la Democracia en el Perú 1810-1827, Lima, Institut Francais d'Etudes Andines e Instituto de Estudios Peruanos, 2012a, 151-170.

Gálvez Peña, Carlos: «Obispo, financista y político: el doctor don Feliciano de Vega y Padilla (1580-1641)», Histórica, XXXVI-1, Lima, 2012b, 97-133.

González de Acuña, fray Antonio: Informe a Nuestro Padre General de la Orden de Predicadores, Fray Joan Baptista de Marinis, le ofrece el presentado Fray Antonio González de Acuña, catedrático de Prima de Moral, Procurador de la Real Universidad de los Reyes, definidor de la Provincia de San Joan Baptista del Perú, Madrid, 1659.

Herrejón Peredo, Carlos: Del Sermón al Discurso Cívico. México: 1760-1834, México, El Colegio de México, 2003.

Lohmann Villena, Guillermo: «Las Cortes en las Indias», en Las Cortes de Castilla y León, 1188-1988. Actas de la Tercera Etapa del Congreso Científico sobre la Historia de las Cortes de Castilla y León, Valladolid, Cortes de Castilla y León, 1990, 591-623.

López de Aguilar, Gregorio: Discurso del mejor arbitrio de Philipo IIII el grande rey de las Españas y emperador de las Indias. Elección de María Santísima Señora Nuestra por patrona de su Española monarchía y protectora de sus cathólicas armas. Predicado en el solemnísimo novenario que por orden de Su Magestad se celebró en la cathedral metropolitana desta corte de Lima, por el P. Gregorio López de Aguilar theólogo y catedrático de philosophía de la Compañía de Jesús. Escrito por mando de Su Excelencia el señor marqués de Mancera, Lima, 1644.

Luque Talaván, Miguel: Un universo de opiniones. La literatura jurídica indiana, Madrid, CSIC, 2003.

Martínez-Serna, Gabriel: «Procurators and the Making of the Jesuits' Atlantic Network», en Bernard Baylin y Patricia L. Denault (eds.), Soundings in Atlantic History, Latent Structures and Intellectual Currents, 1500-1830, Cambridge y Londres, Harvard University Press, 2009, 181-209.

Mispilívar, fray Bernardo de: Sagrado Arbitrio. Commutación de Comedias de Corpus en una Octava Solemne al Santíssimo Sacramento. Rendimiento Penitente para aplacar las iras divinas en un temblor grande manifestadas, 
pacificar la monarquía e imprecar prosperidades a Nuestro Rey y Señor Carlos Segundo...que predicó el P. Fr. Bernardo de Mispilívar, catedrático de Prima y regente mayor en el colegio de San Pedro Nolasco, Lima, Luis de Lyra, 1679.

Pease García Yrigoyen, Franklin: Las crónicas y los Andes, Lima, Fondo de Cultura Económica y Pontificia Universidad Católica del Perú, 1995.

Pérez-Fortea, Ignacio: «An Unbalanced Representation: The Nature and Functions of the Cortes of Castile in the Habsburg Period (1538-1698)», en Jansson, Maija (ed.), Realities of representation. State Building in Early Modern Europe and European America, New Hampshire y New York, Palgrave Macmillan, 2007, 149-170.

Pérez Ramos, Demetrio: «Llamamientos a ciudades de Indias para cortes de Castilla en el siglo XVII» en Las cortes de Castilla y León 1188-1988. Actas de la Tercera Etapa del Congreso Científico sobre la Historia de las Cortes de Castilla y León, Valladolid, Cortes de Castilla y León, 1990, 647-662.

Rowlings, Helen: «Arbitrismo and the Early XVIIth Century Spanish Church: The Theory and Practice of Anti-Clericalist Philosophy», en Pym, Richard (ed.), Rhetoric and Reality in Early Modern Spain, London, Tamesis, 2006, 25-40.

Salinas y Córdova, fray Buenaventura de: Memorial de las Historias del Nuevo Mundo Pirú [1630], edición de Warren Cook, Lima, Universidad Nacional Mayor de San Marcos, 1957.

Salinas y Córdova, fray Buenaventura de: Memorial del P. B. de Salinas y Córdova, Procurador General de la ciudad de Lima...cuya grandeza y méritos representa a la magestad del rey nuestro señor D. Felipe IIII católico monarca en ambos mundos para que pida a su santidad la canonización de su apostólico patrón el venerable Padre Fray Francisco Solano, Madrid, 1639.

Schilling, Heinz: Early Modern European Civilization and its Political and Cultural Dynamism, Hanover y Londres, Brandeis University Press e Historical Society of Israel, 2008.

Skinner, Quentin: The Foundations of Modern Political Thought. Volume Two: The Age of Reformation, Cambridge, New York, Melbourne, Madrid, Singapore, Sao Paulo, Delhi, Mexico City, 2012. 